\title{
Precision in Additive Manufacturing, Optimization AND Evaluation of the ACCURACY OF 3D PRinter BASED ON GPS SYSTEM
}

\author{
Osman Bodur, Vojtech Stepanek, Eva Maria Walcher \& Numan Durakbasa
}
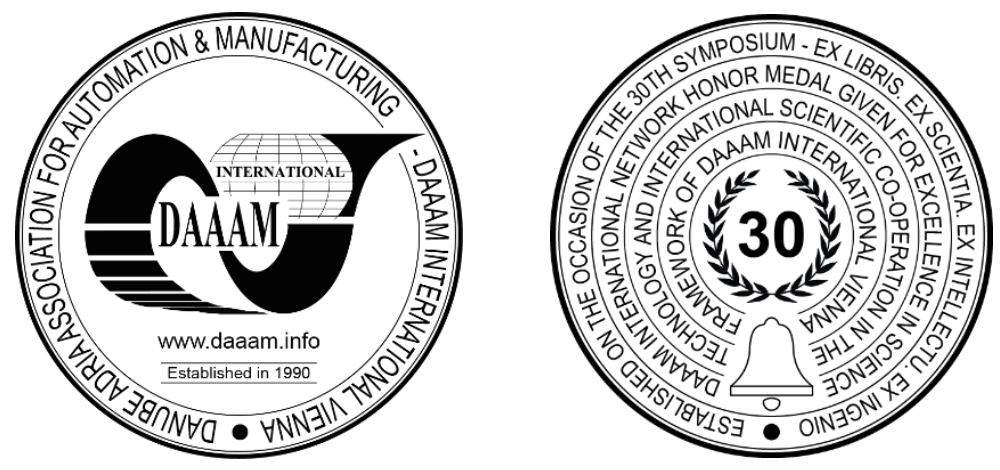

This Publication has to be referred to: Bodur, O[sman]; Stepanek, V[ojtech]; Walcher, E[va] M[aria] \& Durakbasa, N[uman] (2020). Precision in Additive Manufacturing, Optimization and Evaluation of the Accuracy of 3D Printer based on GPS System, Proceedings of the 31st DAAAM International Symposium, pp.0963-0972, B. Katalinic (Ed.), Published by DAAAM International, ISBN 978-3-902734-29-7, ISSN 1726-9679, Vienna, Austria

DOI: $10.2507 / 31$ st.daaam.proceedings. 134

\begin{abstract}
The additive manufacturing method finds increasing usage in the Industry and replaces many other traditional production methods. It is a significant part of Industry 4.0 due to its remote controllability, rapid production capability, and easily generative-sophisticated production dexterity. In modernized production, manufacturing systems ought to be utilized and integrated with the quality control and assurance which provides to produce properly according to the functional specifications and geometrical specifications of the products at the demanded level by characterized standards and GPS systems. Nowadays, FDM (Fused Deposition Modelling) is the most commonly used and cost-oriented additive manufacturing technique that makes it an obtainable and affordable alternative compared to other additive methods. In light of this information, the scope of this research is to establish a strategic approach to implement the FDM in the advanced manufacturing industry providing intelligent networking systems by data transfer and communication in production design, manufacture, metrology, and quality management systems.
\end{abstract}

Keywords: Additive manufacturing; geometrical product specifications; reverse engineering; Industry 4.0; statistical process control

\section{Introduction}

The developments and trends through modern intelligent production systems provide data transfer automatically and fast communication between each product design, manufacturing departments, and quality management systems in the circumference of Industry 4.0. The demands have been increasing for intelligent, cost-oriented, and flexible systems in this area. The automation of a production process with the integration of quality standards and management systems is one of the most significant philosophies of Industry 4.0 which is included advanced manufacturing and high precision measurement technologies [1], [2]. The purposes of that research are to evaluate the printing ability of FDM according to ISO dimensional standard and GPS through the contouring test piece, to carry out the more accurate geometrical structures of the products, and to optimize the accuracy of the product positioning of the 3D printer depending on stepper motors and synchronous belts by using an iteratively compensational approach within the frame of reverse engineering and Industry 4.0. 
This compensation approach brings new possibilities for using less precision 3D printers to make more precise printed parts. The modest close loop is easy to use and it has the potential to be widespread in many areas of additive manufacturing. Further research will be focused on the examination of each feature shape and also improve the geometrical tolerances.

Improvements in precision technology combine and evaluate the functional and geometrical specification information of the product and digital techniques in the stage of production with quality management systems. Focusing on the digitalization of the product life cycle in the industry increases the competitiveness of the companies incorporated with a knowledge-based economy [3], [4]. CAD ${ }^{1}$, Additive manufacturing, and $\mathrm{CAQ}^{2}$ unite the diversified assignments of the reaction between evaluation, quality optimization, examination, precision engineering, and related management systems in Industry 4.0 and Moreover, the research follows these steps:

- Establishing of product geometry and geometrical tolerances according to functional and geometrical specifications,

- Integrating the CAD data to manufacture the product by intelligent networking system,

- Planning the examination of metrology data by advanced measurement software,

- Creating of remote-control data to measure automatically,

- Realizing the measurement by high precision measurement technology,

- Analyzing and evaluating the measurement results statistically,

- Importing the statistical evaluation and analysis to the CAD system and additive manufacturing,

- Redesign the product geometry according to the evaluation parameters by CAQ,

- Implementing the corrections in the production by including measurement-oriented data [5].

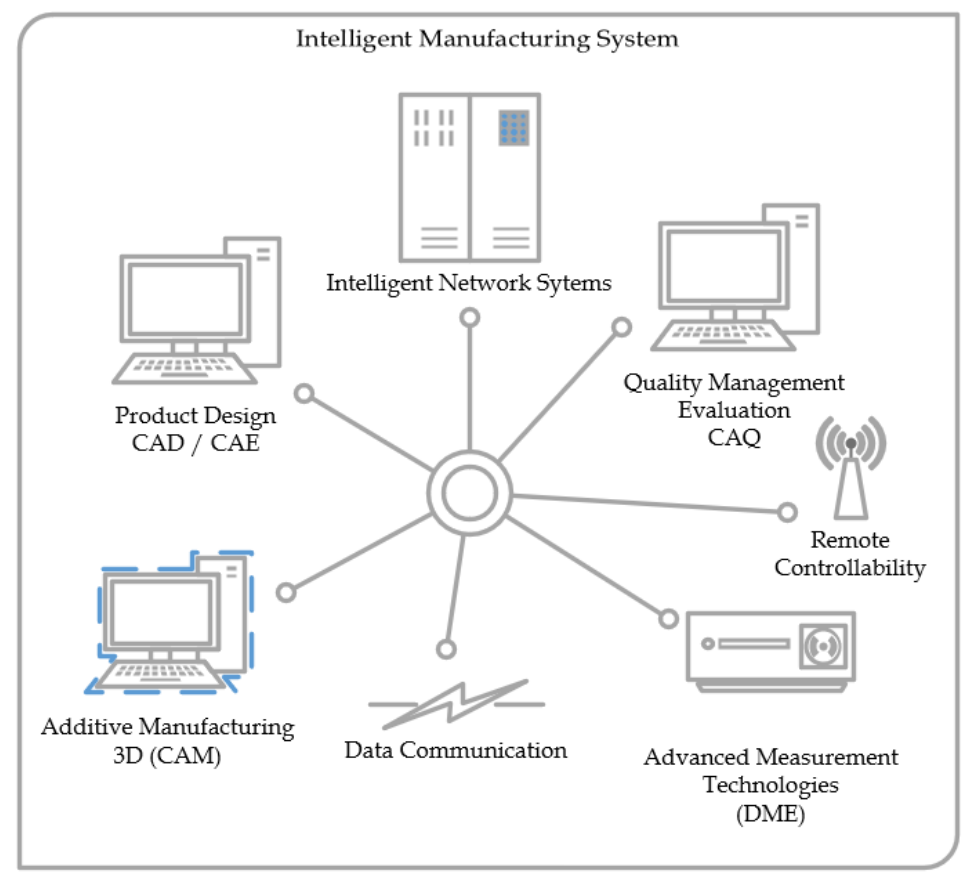

Fig. 1. Intelligent Manufacturing Systems in Industry 4.0

Intelligent manufacturing systems pave the way for better knowledge of the manufacturing process, increasing the product innovation combining the high-quality functional requirements and precision metrology as seen in Fig. 1. Additive manufacturing also forms a part of the Industry 4.0 system due to its several specifications as non-complex manufacturing methods by transferring the CAD data within the server, reducing the production time, decreasing the manufacturing cost, producing the complicated shapes are some of them [6]. Besides, decreasing the weight of the workpiece and the power consumption are the other advantages of the additive manufacturing technique. The printed parts shall be examined by metrology activities after the printing operation whether they are represented the skin geometrical specifications compared to the existed physical features [7]. In rapid prototyping technology (RP), highly accurate $3 \mathrm{D}$ printing is becoming increasingly important [8].

Industry 4.0 transformed traditional manufacturing to digital manufacturing by intelligent network systems and describes the methodology with nine pillars: Cyber-Physical Systems, Industrial Internet of Things, the Cloud Computing, Big Data and Analytics, System Integration: Horizontal and Vertical System Integration, Simulation, Autonomous Robots, Additive Manufacturing (3D printers), Augmented Reality [9], [10]. Cyber-Physical Manufacturing Metrology appears a very useful method for reverse engineering.

${ }^{1}$ CAD: Computed Aided Design

${ }^{2}$ CAQ: Computed Aided Quality 


\section{Methods and Theoretical Parts}

This chapter of the paper is focused on the geometrical specifications of additive manufacturing and printed test piece, FDM manufacturing method and slicing parameters, evaluation of statistical process control, and compensational approach to optimize the accuracy of 3D printer.

\subsection{Geometrical Specifications}

The standard ISO 10791-7 describes the shape of the test piece for three-axis CNC machines. Besides, the 3D printer uses the three-axis Cartesian coordination system too and the original test pieces for 3D printers are commonly focused on filament extraction or the visual evaluation of the printed part. Therefore, the printed workpiece was an $80 \mathrm{x} 80 \mathrm{~mm}$ test piece according to ISO 10791-7 with the dimensions as seen in Fig. 2. [11].

Standard ISO 2768 describes the commonly used tolerances for the dimension without specific assignment by the designer. There are four levels of tolerances for linear and angular dimensions (f - like fine, the highest precision, $\mathrm{m}$ for medium, $\mathrm{c}$ for coarse, and $\mathrm{v}$ - the lowest precision like very coarse). The most frequently used is the second tolerance level $\mathrm{m}$. The same tolerance level has been used for each dimension of the printed test piece [12].
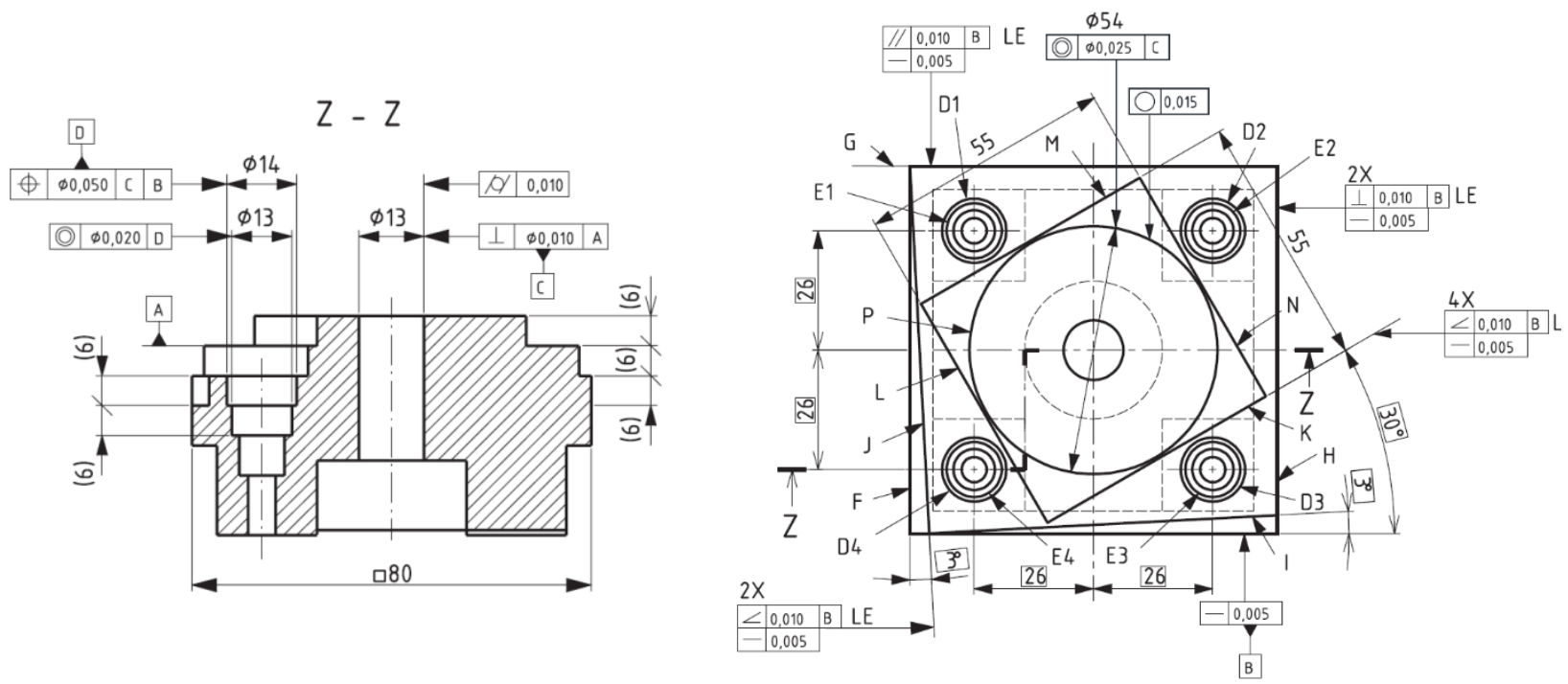

Fig. 2. The size of contouring test piece ISO 10791-7, M1_80, and the dimensions [11].

The international standard ISO 1101 specifies the basic requirements for geometric specifications of workpieces. It describes the basics of geometric tolerances and has to be functional functions. The tolerance zone depends on the tolerating feature and dimensioning and is arranged normal to the theoretically exact feature (TEF), which is perfect in its geometry. If the theoretical location, direction, and profile of a geometric element are specified exactly, then this is called the theoretically exact dimension (TED). The definitions of the geometric tolerances with practical examples are described in ISO 1101:2020 [13].

In general, there are two main categories of general geometrical tolerances, the tolerances for single features and the tolerances for related features. Tolerances for single features include straightness and flatness, circularity, and cylindricity. Tolerances for related features are tolerances where all features are concerning on another, like perpendicularity, parallelism, symmetry, coaxiality, and circular run-out [14].

Perpendicularity tolerance exists if the theoretical angle between the tolerates nominal geometry element and the datums have a theoretical dimension of $90^{\circ}$. Perpendicularity has the symbol " $\perp$ ". A geometrical element has parallel tolerance if the implied theoretical angle between the tolerates nominal geometry element and the datum is " 0 "'. Parallelism has the symbol "//". Angularity tolerance refers between an exact theoretical angle and its datum of a tolerate nominal geometric element. [13].

Additive manufacturing is divided into three process flows. All additive manufacturing processes are already improved in the first pre-processing so that the component can be used in the next in-process with a certain accuracy. In addition to the positioning of the part and the hardware, data preparation is a very important point in the pre-process. The last step is post-processing if necessary [15]. After the manufacturing process, every additively manufactured component must answer certain geometric product specifications. Table 1 shows the artistic and geometric requirements for relevant quality characteristics. The additive manufacturing of components makes economic and technological sense only if the quality criteria and geometric product specifications are complied with. 


\begin{tabular}{|l|l|}
\hline Performance criteria & Relevant quality characteristics \\
\hline Creative requirements & $\begin{array}{l}\text { size, scale, mass, density, visible edges and surface structures, color, transparency, feel, } \\
\text { smell }\end{array}$ \\
\hline Geometric requirements & $\begin{array}{l}\text { component size and complexity, length and angle dimensions, dimensional tolerances, } \\
\text { deviations in shape and position, shrinkage behavior, minimum structures, walls, slits, } \\
\text { and layer thicknesses }\end{array}$ \\
\hline
\end{tabular}

Table 1. Performance criteria and quality characteristics of components for additive manufacturing performance [15]

\subsection{FDM ${ }^{3}$ Additive Manufacturing}

The additive manufactured parts as prototypes, instruments or components have various using and practicing fields in architecture, medicine, engineering, and geosciences [16]. One of the additive manufacturing methods is Fused Deposition Modelling which is based on layering the filaments over and over to create a physical model depending on the STL or $\mathrm{AMF}^{4}$ data file. The principle of the FDM technique is which thermoplastic filament is elasticized with high temperature, settled by heated nozzle then the layers placed on top of each other are immediately cooled by the help of a fan after extrusion [15]. This manufacturing methods occasionally entail the support structures, in consequence of the limited modelling capabilities [17].

Ones of the data formats are STL ${ }^{5}$ and AMF that is used for 3D viewing, analysis, and slicing the printed parts between production design and additive manufacturing technique. STL divides the surface geometry of a solid design as a tessellation of triangles [16]. AMF is a written format occurred by from original geometric data of part, can be read as content form by both humans and machines, and structures the geometric data as $\mathrm{XML}^{6}$ which is an electronic format and an extensible mark-up language [18].

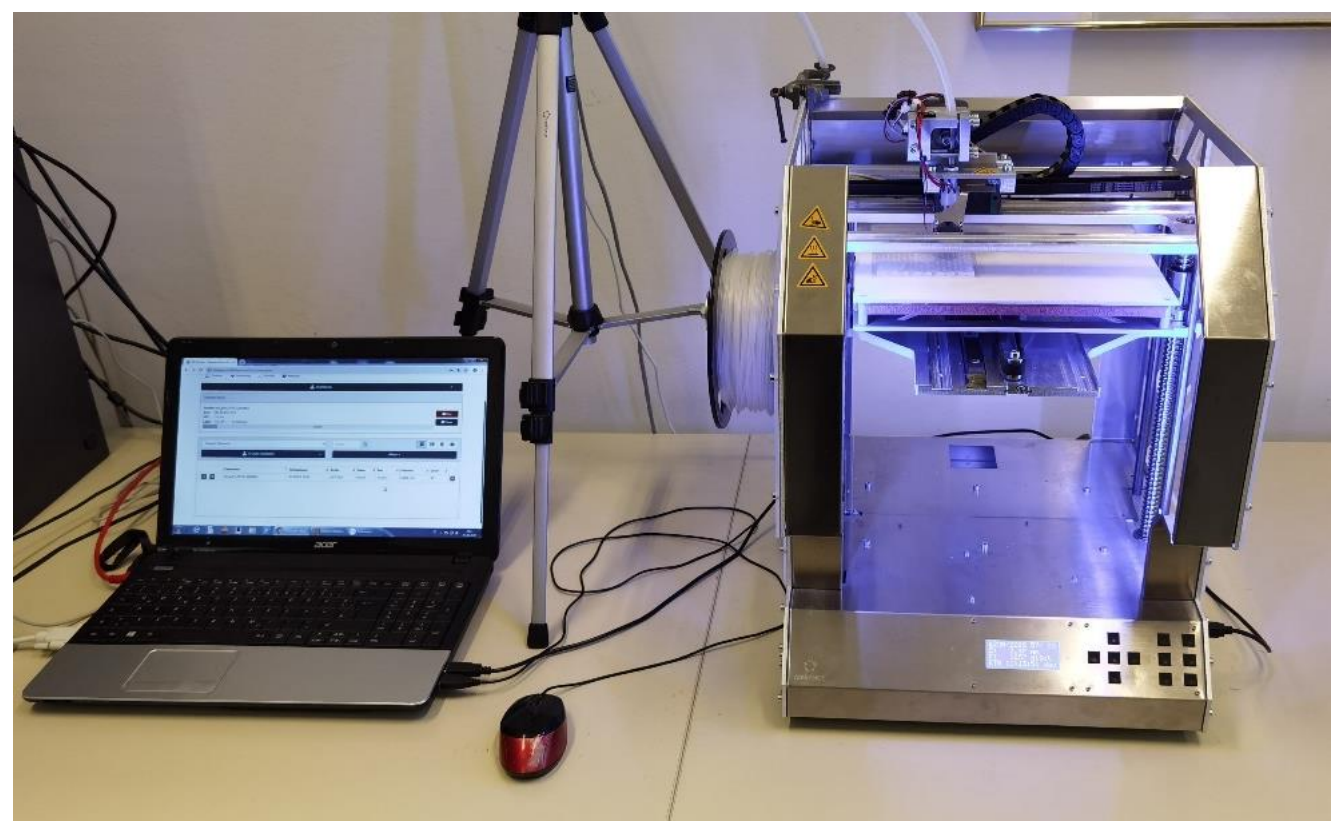

Fig. 3. FDM 3D printer

As seen 3D printer, in Fig 3., is able to use for printing for filament diameter 2,85 or 3mm from a wide range of material $\left(\mathrm{PLA}^{7}, \mathrm{ABS}^{8}, \mathrm{PETG}^{9}, \mathrm{PA}^{10}, \mathrm{PC}^{11}, \mathrm{PP}^{12}\right.$, and others). The positioning accuracy of the extruder is not specified so only the thickness of each layer between 0,05 and $0,3 \mathrm{~mm}$.

\footnotetext{
${ }^{3}$ FDM: Fused Deposition Modeling

${ }^{4}$ AMF: Additive Manufacturing File Format

${ }^{5}$ STL: Standard Triangle Language, format used for rapid prototyping and 3D printing

${ }^{6}$ XML: Extensible Markup Language

${ }^{7}$ PLA: Polylactic acid

${ }^{8}$ ABS: Akrylonitrilbutadienstyren

${ }^{9}$ PETG: Polyethylene terephthalateco-1, 4-cylclohexylenedimethylene terephthalate

${ }^{10}$ PA: Polyamide

${ }^{11}$ PC: Polycarbonate

${ }^{12}$ PP: Polypropylene
} 


\begin{tabular}{|l|l|l|}
\hline Filament diameter & 2,85 & $\mathrm{~mm}$ \\
\hline Filament material & PLA & \\
\hline The Extruder temperature $\left[1^{\text {st }}\right.$ layer/other layers] & $230 / 220$ & ${ }^{\circ} \mathrm{C}$ \\
\hline The Bed temperature $\left[1^{\text {st }}\right.$ layer / other layers] & $60 / 55$ & ${ }^{\circ} \mathrm{C}$ \\
\hline The Extruder Cooling & Fan always ON & \\
\hline The Layer height $\left[1^{\text {st }}\right.$ layer $/$ other layers] & $0,35 / 0,2$ & $\mathrm{~mm}$ \\
\hline Number of solid layers [Top/Bottom] & $3 / 3$ & {$[-]$} \\
\hline Infill density & 15 & $\%$ \\
\hline Fill angle & 45 & $\mathrm{DEG}$ \\
\hline Solid infill threshold area & 5 & $\mathrm{~mm}^{2}$ \\
\hline Brim width around the part & 5 & $\mathrm{~mm}$ \\
\hline Speed for printing Perimeters & 70 & $\mathrm{~mm} / \mathrm{s}$ \\
\hline Speed for printing Infill & 70 & $\mathrm{~mm} / \mathrm{s}$ \\
\hline Speed for Top solid infill & 45 & $\mathrm{~mm} / \mathrm{s}$ \\
\hline First layer speed & 50 & $\%$ \\
\hline
\end{tabular}

Table 2. 3D printer settings and slicing parameters

\subsection{Evaluation of Statistical Process Control}

The importance of quality control and statistical process control in Industry 4.0 is increasing. Data is collected and improved in an automated process related to Predictive Quality Management [8]. One of the significant parameters of SPC is to comprehend the system, functional, and geometrical specifications limits [19]. The repeatability of the printing process is not unmitigated. Many factors influence manufacturing precision. As the most common examples, the temperature, filament homogeneity, or machine condition could be mentioned. The two types of errors arise the systematical error and the random error. The statistical evaluation shall be done to calculate these parameters and describe the measured values [20]. The most essential elements are described in the following chapter.

\subsubsection{Upper (USL) and Lower (LSL) specification limit}

The standard ISO 2768-m specify the upper and lower specification limit by the size of the tolerance field according to Eq.1. and Eq.2. for each length or angular dimension. The range of the tolerance field is depended on the size of the dimension and the size of the described feature. For this feature is the tolerance field depended only on the dimension value. According to Fig. 4. below, for a nominal value equal to 27.5 and the class of accuracy " $m$ " is the common tolerance field equal to $\pm 0.2 \mathrm{~mm}$.

$$
\begin{aligned}
& \boldsymbol{U} \boldsymbol{S} \boldsymbol{L}^{13}=x_{\text {nom }}{ }^{14}+t^{15} \\
& \boldsymbol{L} \boldsymbol{S} \boldsymbol{L}^{16}=x_{\text {nom }}-t
\end{aligned}
$$

\begin{tabular}{|c|c|c|c|c|c|c|c|c|c|}
\hline \multirow{2}{*}{\multicolumn{2}{|c|}{ Tolerance class }} & \multicolumn{8}{|c|}{ Permissible deviations for basic size range } \\
\hline & & \multirow{2}{*}{$\begin{array}{c}0.5^{11} \\
\text { up to } \\
3\end{array}$} & \multirow{2}{*}{$\begin{array}{c}\text { over } \\
3 \\
\text { up to } \\
6\end{array}$} & \multirow{2}{*}{$\begin{array}{c}\text { over } \\
6 \\
\text { up to } \\
30\end{array}$} & \multirow{2}{*}{$\begin{array}{c}\text { over } \\
30 \\
\text { up to } \\
120 \\
\end{array}$} & \multirow{2}{*}{$\begin{array}{c}\text { over } \\
120 \\
\text { up to } \\
400\end{array}$} & \multirow{2}{*}{$\begin{array}{c}\text { over } \\
400 \\
\text { up to } \\
1000\end{array}$} & \multirow{2}{*}{$\begin{array}{l}\text { over } \\
1000 \\
\text { up to } \\
2000\end{array}$} & \multirow{2}{*}{$\begin{array}{l}\text { over } \\
2000 \\
\text { up to } \\
4000\end{array}$} \\
\hline Designation & Description & & & & & & & & \\
\hline$f$ & fine & $\pm 0,05$ & $\pm 0,05$ & $\pm 0,1$ & $\pm 0,15$ & $\pm 0,2$ & $\pm 0,3$ & $\pm 0,5$ & - \\
\hline m & medium & $\pm 0,1$ & $\pm 0,1$ & $\pm 0,2$ & $\pm 0,3$ & $\pm 0,5$ & $\pm 0,8$ & $\pm 1,2$ & \pm 2 \\
\hline c & coarse & $\pm 0,2$ & $\pm 0,3$ & $\pm 0,5$ & $\pm 0,8$ & $\pm 1,2$ & \pm 2 & \pm 3 & \pm 4 \\
\hline $\mathbf{v}$ & very coarse & - & $\pm 0,5$ & \pm 1 & $\pm 1,5$ & $\pm 2,5$ & \pm 4 & \pm 6 & \pm 8 \\
\hline
\end{tabular}

Values in millimetres

Fig. 4. Permissible deviations for linear dimensions except for broken edges [12]

\footnotetext{
${ }^{13}$ USL : Upper Specification Limit

${ }^{14} \mathrm{X}_{\text {nom }} \quad$ : Nominal (required) value of the dimension

${ }^{15} \mathrm{t} \quad$ : Tolerance range described in standard ISO $2768-1$

${ }^{16}$ LSL : Lower Specification Limit
} 


\subsubsection{Process capability index $(\mathrm{Cp})$}

One of the trends in Industry 4.0 is the production accuracy improving. For the prediction the capability of the manufacturing process, the statistical approach has to be used. The commonly used parameters are the process capability indices. The first parameter Cp in Eq.3. is the most important parameter because its value decides that the process is accurate enough to abide by the precision requirements. The $\mathrm{Cp}$ index minimum value was determined to the 1.33 to get the waste-free production. The next parameter computable by Eq.4. is the Cpk index. The Cpk index shows the position of the mean value in the tolerance range. If the $\mathrm{Cpk}$ index equal to $\mathrm{Cp}$ than the mean value is in the middle of the tolerance range. If the Cpk index is less than zero, the mean value lies out of the tolerance range [20].

$$
\begin{aligned}
& C_{p}=\frac{U S L-L S L}{6 \sigma}[-] \\
& C_{p k}=\operatorname{MIN}\left\{\frac{U S L-\bar{x}}{3 \cdot \sigma} \mid \frac{\bar{x}-L S L}{3 \cdot \sigma}\right\}[-]
\end{aligned}
$$

The process capability index $\mathrm{Cp}$ is the statistical parameter. The value of the process capability index shows the ability of the production machine to hold the real values in the tolerance range. $\mathrm{Cp}$ index can achieve values $>=0$. Cp index would be zero in case if the range of the tolerance field is equal to zero. If the $\mathrm{Cp}$ index is equal to 1, the range of tolerance field is equal to $6 \sigma$. The real measured value after production will be in the tolerance zone with a 99.7 percent probability. In the industry, the common minimum value for the $\mathrm{Cp}$ factor is 1.3 [20].

\subsection{Compensation approach}

The compensation approach is based on parametrical adjustment of the mean value using the change of STL ${ }^{17}$ data for printing. Small example, the required value of the dimension is $25 \mathrm{~mm}$ but the mean value of the dimension of the real printed part is $24.6 \mathrm{~mm}$. The self-optimization algorithm shown in Fig.5 gets the previous value of the dimension parameter in a virtual model and adds the compensation parameter $\operatorname{dim}_{\text {err }}{ }^{18}$ evaluated by Eq.5.

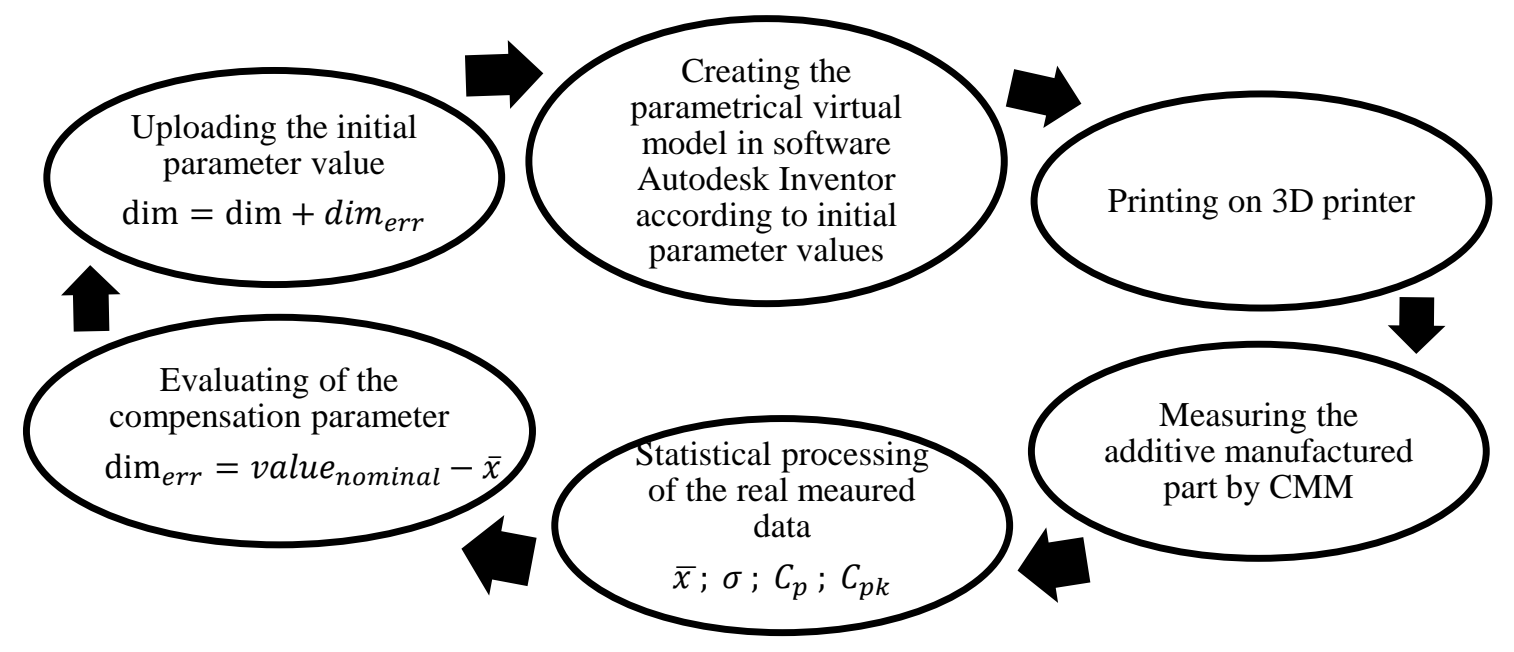

Fig. 5. Self-optimizing Close Loop

$$
\begin{aligned}
& \operatorname{dim}_{\text {err }}=\text { value }_{\text {nominal }}-\bar{x} \\
& \operatorname{dim}=d i m+\operatorname{dim}_{\text {err }}
\end{aligned}
$$

\section{Results}

The experiment started with the nominal dimensions of the test piece specified in the technical drawing. The 1 st fivepart were printed with the same printer settings, the same part position in the workspace, the same slicer method described

\footnotetext{
${ }^{17}$.stl - data format of the virtual 3D model

${ }^{18} \mathrm{dim}_{\mathrm{err}}$ - compensation parameter. It is negatively taken deviation the real value from nominal dimension
} 
in Table 2. The measurement was carried out for every part end the measured values have been copied and reformulated from the original CMM protocol to the own document created in spreadsheet software. For each feature, the mean measured value and the standard uncertainty of measurement $(\sigma)$ have been evaluated.

To create the virtual solid model of the test piece the designer software has been used. The part is made by the parametrical approach. The parameters are imported from spreadsheet software. The initial dimension parameter of each feature is set to the nominal value specified in the ISO 10791-7 standard.

Example of processing feature data - the distance between base $\mathrm{C}$ and Right down rhombus side: The base $\mathrm{C}$ is obtained as a reference dimension at the beginning of the measurement. The rhombus is created by 8 parametrical dimensions, especially $30^{\circ}$ to base B (the downside), 2 perpendicular dimensions, 1 parallelism, and 4 perpendicular distances to base $\mathrm{C}$. this paragraph below is focused on the correction of the perpendicular distance between the base $\mathrm{C}$ and right down rhombus side. First of all, the 5 initial parts without any correction have been printed and measured. Obtained measured values are in Table 3. According to this measurement, the initial dimension values have been obtained according to Eq.6.

\begin{tabular}{|c|c|c|c|c|c|c|c|}
\hline NAME OF THE FEATURE & $\begin{array}{c}\text { NOMINAL } \\
\text { VALUE } \\
\text { [MM] }\end{array}$ & $\begin{array}{c}\text { 1ST } \\
\text { PART } \\
\text { VALUE } \\
\text { [MM] }\end{array}$ & $\begin{array}{c}\text { 2ND PART } \\
\text { VALUE } \\
\text { [MM] }\end{array}$ & $\begin{array}{c}\text { 3RD PART } \\
\text { VALUE } \\
\text { [MM] }\end{array}$ & $\begin{array}{c}\text { 4TH PART } \\
\text { VALUE } \\
\text { [MM] }\end{array}$ & $\begin{array}{c}\text { 5TH PART } \\
\text { VALUE } \\
\text { [MM] }\end{array}$ & $\begin{array}{c}\text { AVERAGE } \\
\text { VALUE } \\
\text { [MM] }\end{array}$ \\
$\begin{array}{c}\text { Distance between WCC } \\
\text { and right down rhombus } \\
\text { side }\end{array}$ & 27,500 & 27,265 & 27,273 & 27,246 & 27,312 & 27,265 & 27,272 \\
\hline
\end{tabular}

Table 3. Measured values before compensation

After printing, the temperature of the printed part has been equalized to the laboratory temperature, because the thermal expansion coefficient of the PLA equal to $80.10-7$ m.m-1K-1 may cause the dimensional error during the measurement. The measurement has been done on the coordinate measuring machine. The offline measuring program for probing has been made according to .stp virtual part from the standard ISO 10791-7 (80x80).

For this dimension is the $\mathrm{Cp}$ factor equal to 3,03 by calculating with the Eq. 3. It is possible to indicate this $3 \mathrm{D}$ printer as eligible to print this feature of the part in the tolerance field specified in ISO 2768-m. But this phenomenon applies only in the case that the mean value is equal to the nominal value. The degree of compliance can be evaluated by the Cpk factor. The Cpk factor cannot be more than $\mathrm{Cp}$. If the $\mathrm{Cpk}$ factor is equal to the $\mathrm{Cp}$ factor, the mean value from the 5 measured part is equal to the nominal value. If the Cpk factor is equal to 0 , the mean value is equal to USL or LSL. If the value of Cpk is less than 0 , the mean value is out of range of the tolerance field. The result of -0.424 for this dimension (evaluation below) points to that this dimension is out of the range of the tolerance field and has to be compensated. This method described in chapter 2.4 is applied to each dimension on the workpiece that is intended to compensate and get the real dimension in the required tolerance range [20].

For every measured value has been decided whether it is located in the tolerance field according to ISO 2768-m (green highlighting for the correct value, red for values out of tolerance). The correction value of the .stl data is created as the difference between the required nominal value and the mean value of the dimensional error for each feature from 5 printed parts. The last step is to add the correction value to the previous dimension parameters of .stp. The best way how to show the measured data is the graph. There are depicted 4 ranges of measured values in the graph. The hatched zone represents the tolerance field for this dimension according to ISO $2768-\mathrm{m}$. The red zone is the zone - nominal value $\pm 3 \sigma$. The most measured values on the real part should be found in this area. The yellow and green zones are the multiples of the previous red zone. Five points in the left down part of the graph is the graphical displaying measured values before compensation. As it is obvious, four from five points occur out of the tolerance range. Instead, all five points lie in the $\pm 3 \sigma$ area around the nominal value and the mean value of measured points is approaching closer to the required nominal value in the middle of the tolerance range [12], [20].

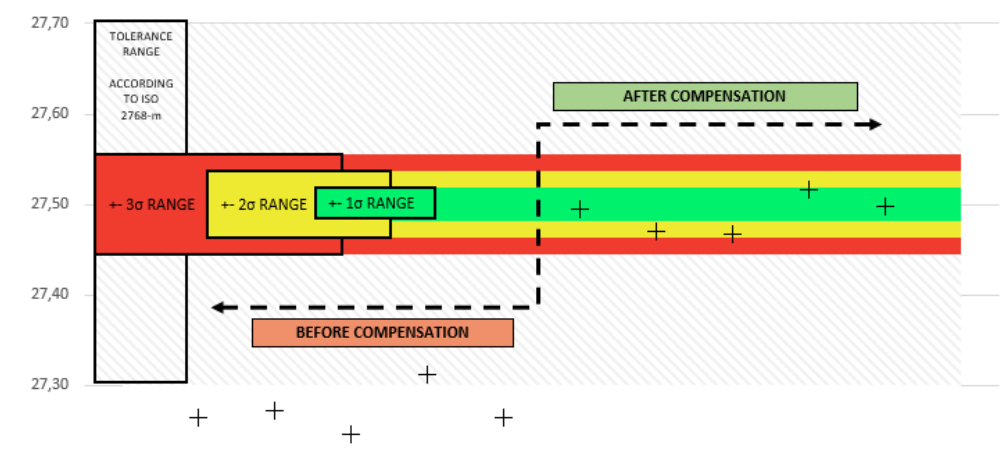

Fig. 6. Graphical expression of the statistical processing of the measured data before and after compensation 
After two iteration processes, the next 5 parts have been printed and the statistic evaluation has been executed. The progress in dimension can be seen in the results in Table 4 . The mean value approximates the required nominal value and every measured value is in the tolerance field specified in ISO 2768-m. In Fig 8. there is a comparison between the compensated part and the previous one.

\begin{tabular}{|c|c|c|c|c|c|c|}
\hline $\begin{array}{l}\text { NAME OF THE } \\
\text { FEATURE }\end{array}$ & \multicolumn{3}{|c|}{$\begin{array}{l}\text { Distance between WCC and right down } \\
\text { rhombus side }\end{array}$} & \multicolumn{2}{|c|}{ NOMINAL VALUE } & $27,500 \mathrm{MM}$ \\
\hline MEASURED VALUE & $\begin{array}{c}\text { 1ST PART } \\
\text { VALUE } \\
\text { [MM] }\end{array}$ & $\begin{array}{c}\text { 2ND PART } \\
\text { VALUE } \\
\text { [MM] }\end{array}$ & $\begin{array}{c}\text { 3RD PART } \\
\text { VALUE } \\
\text { [MM] }\end{array}$ & $\begin{array}{c}\text { 4TH PART } \\
\text { VALUE } \\
\text { [MM] }\end{array}$ & $\begin{array}{c}\text { 5TH PART } \\
\text { VALUE } \\
\text { [MM] }\end{array}$ & MEAN VALUE [MM] \\
\hline $\begin{array}{c}\text { BEFORE } \\
\text { COMPENSATION }\end{array}$ & 27,265 & 27,273 & 27,246 & 27,312 & 27,265 & 27,272 \\
\hline $\begin{array}{c}\text { AFTER } \\
\text { COMPENSATION }\end{array}$ & 27,495 & 27,470 & 27,467 & 27,516 & 27,498 & 27,489 \\
\hline STATISTIC & $\sigma$ & USL & LSL & Cp & Cpk & ACCURACY \\
\hline $\begin{array}{c}\text { BEFORE } \\
\text { COMPENSATION }\end{array}$ & 0,022 & \multirow{2}{*}{27,700} & \multirow{2}{*}{27,300} & 3,059 & $-0,425$ & [\%] \\
\hline $\begin{array}{c}\text { AFTER } \\
\text { COMPENSATION }\end{array}$ & 0,018 & & & 3,625 & 3,430 & 95,259 \\
\hline
\end{tabular}

Table 4. Comparison of the real dimensional values

The percentage improvement evaluated according to Eq. 7. of some dimension is also up to $99 \%$ from the state before compensation. Some features have a negative percentage improvement. The accuracy before compensation was so accurate that every next compensation attempt is the same or a little bit worse. This phenomenon is caused by the limited repeatability of the 3D printer [21]. But the most important is to stay in the tolerance zone for every dimension on the printed part and this factor has complied with the requirements. In Fig. 7. there is depicted the technical drawing of the virtual model before and after compensation. Insomuch as the dimensional errors are too small beside the workpiece dimension, the technical drawing is zoomed to the left bottom corner of the workpiece described in Fig. 6.

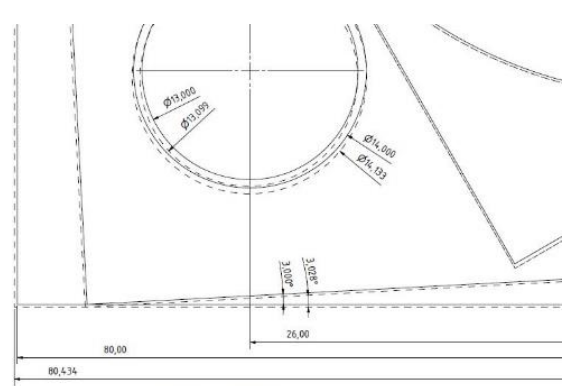

Fig. 7. Dimensions of the virtual model before (full line) and after (dashed line) compensation

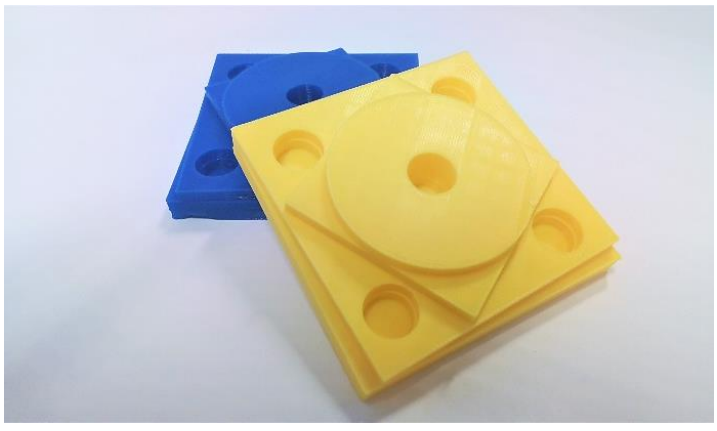

Fig. 8. Real parts before (blue) and after (yellow) compensation

For the verification of the improvement of this approach, the two iteration steps have been done. Before compensation, after measuring the 45 observed dimensions (225 measured values) of many types of the features of the ISO test part, every $4^{\text {th }}$ value was located out of the tolerance range. After compensation, there is only 1 feature $\mathrm{z} 45$, which is out of the tolerance field. But the $\mathrm{Cp}$ factor according to evaluation number (3) of the incorrect feature is equal to 1,721, so the repeatability of this feature is extensive enough to compensate for the value in the next iteration attempt. Improvement evaluated by Eq.7. based on the number of the incorrect values before (58) and after (4) is more than 93\% and it is able to mark this compensation approach as successful.

$$
\text { dimension improvement }=\left(1-\frac{\text { incorrect values }_{\text {after }}}{\text { incorrect values }_{\text {before }}}\right) \cdot 100=\left(1-\frac{4}{58}\right) \cdot 100=93,1 \%
$$




\begin{tabular}{|c|c|c|c|c|c|c|}
\hline $\begin{array}{l}\text { NAME OF THE } \\
\text { FEATURE }\end{array}$ & \multicolumn{3}{|c|}{$\begin{array}{l}\text { Perpendicularity between base B and } \\
\text { the left side }\end{array}$} & \multicolumn{2}{|c|}{$\begin{array}{l}\text { NOMINAL GEOMETRICAL } \\
\text { TOLERANCE } \\
\end{array}$} & \multirow{2}{*}{$\begin{array}{c}0,03 \mathrm{MM} \\
\begin{array}{c}\text { MEAN VALUE } \\
\text { [MM] }\end{array}\end{array}$} \\
\hline MEASURED VALUE & $\begin{array}{c}\text { 1ST PART } \\
\text { VALUE } \\
\text { [MM] }\end{array}$ & $\begin{array}{c}\text { 2ND PART } \\
\text { VALUE } \\
\text { [MM] }\end{array}$ & $\begin{array}{c}\text { 3RD PART } \\
\text { VALUE } \\
\text { [MM] }\end{array}$ & $\begin{array}{c}\text { 4TH PART } \\
\text { VALUE } \\
\text { [MM] }\end{array}$ & $\begin{array}{c}\text { 5TH PART } \\
\text { VALUE } \\
\text { [MM] }\end{array}$ & \\
\hline $\begin{array}{c}\text { BEFORE } \\
\text { COMPENSATION }\end{array}$ & 0,121 & 0,107 & 0,124 & 0,002 & 0,078 & 0,0864 \\
\hline $\begin{array}{c}\text { AFTER } \\
\text { COMPENSATION }\end{array}$ & 0,011 & 0,021 & 0,032 & 0,013 & 0,029 & 0,0212 \\
\hline STATISTIC & $\sigma$ & USL & LSL & $\mathbf{C p}$ & Cpk & \multirow{2}{*}{$\begin{array}{l}\text { ACCURACY } \\
\text { IMPROVE- } \\
\text { MENT [\%] }\end{array}$} \\
\hline $\begin{array}{c}\text { BEFORE } \\
\text { COMPENSATION }\end{array}$ & 0,04523 & \multirow{2}{*}{0,01} & \multirow{2}{*}{0} & 0,037 & $-0,56$ & \\
\hline $\begin{array}{c}\text { AFTER } \\
\text { COMPENSATION }\end{array}$ & 0,00835 & & & 0,20 & $-0,447$ & 75,5 \\
\hline
\end{tabular}

Table 5. Comparison of the real geometrical errors before and after compensation

Some geometrical tolerances are not dependent on the dimension. As an example, the roundness is not dependent on the diameter, only on the accuracy of the circular interpolation. The line straightness is depended on the length of the line and deviation of the line from the ideal one. However, the perpendicularity is directly related to the angle dimension [22]. There is a comparison of the perpendicularity geometrical between base B (the lower side) and the left side of the workpiece according to the standard ISO 10791-7 in Fig. 9 and Table 5.

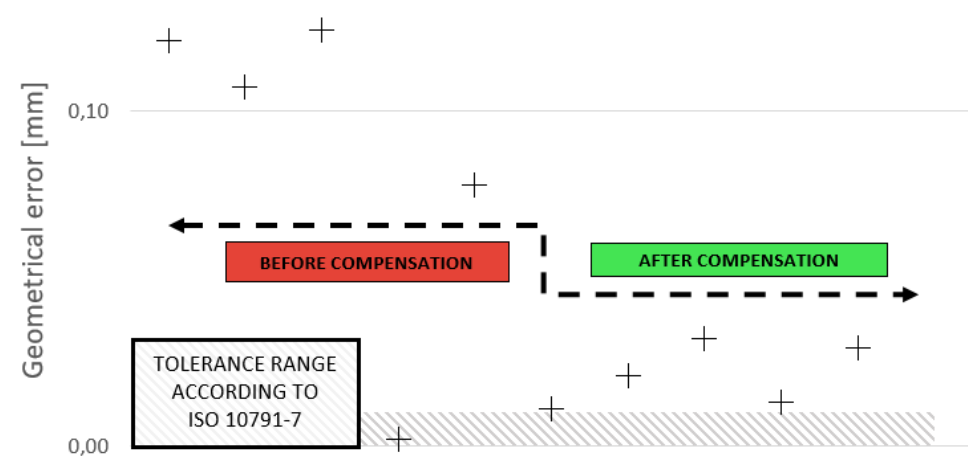

Fig. 9. Geometrical error before and after compensation of the perpendicularity between base B and the left workpiece side

\section{Conclusion}

Additive manufacturing is becoming more important in industrial manufacturing. The production of components is varied, fast, and optimized costs, therefore the area of application of this technology is increasing, e.g. medical technology such as prosthetics, automotive industry, aerospace, architecture. Complicated geometries can be generated without tools, only from 3D CAD data, so you are very flexible besides, the weight is very low.

The requirement for manufacturing precision becomes higher and higher. In the field of Industry 4.0 can stay only machines, which are flexible, more powerful, more precise, and more efficient than each other. The self-optimization approach described in this paper gets satisfactory results. Some features on the printed part have been improved on more than $95 \%$ after the second compensated iteration only. This approach applies to many self-optimizing close loops between the production machine and the measuring machine and helps to comply with requirements of the function surfaces and to get zero-waste production during the whole manufacturing. This compensation approach minimizes the error between the mean value of real measured data and the nominal required value. If the machine has not repeatability enough, there is a random error in the real printed parts and some dimensions can occur out of the tolerance range.

As the next step of improvement of this method, some precise geometrical tolerances would be compensated. In this method, the line is created as a line, circle as a circle. There is a possibility to investigate every measured point alone and create the compensated features by polynomials or other functions and compensate for the shape of the feature, not only the dimension's properties. Of course, it requires the more CMM machine to get the output data applicable to the compensation software. 


\section{Acknowledgments}

These results were obtained with the support of the Faculty of Mechanical Engineering, Brno University of Technology (grant no. FSI- RV90200100329).

\section{References}

[1] Cimini C., Pinto R., Pezzotta G., Gaiardelli P.; The transition towards Industry 4.0: business opportunities and expected impacts for suppliers and manufacturers. In: Lödding H, et al (eds) APMS 2017, Part I, IFIP AICT, vol 513. Springer, Cham, pp 119-126, 2017.

[2] Bodur, O.; Poszvek, G.; Walcher E.; Durakbasa N.M.; Intelligent Design and Advanced Precision Metrology on the Geometrical Structure of Medical Needles Based on GPS and ISO Standards, ISPR 2020, LNME, pp. 1-17, 2020.

[3] Zębala, W., Struzikiewicz, G., Franczyk, E.; Monitoring of Machining in the Context of Industry 4.0 - Case Study, ISPR 2018, Proceedings of the International Symposium for Production Research 2018, pp. 660-673, 2019.

[4] Blecha, P., Durakbasa, N., Holub, M.; Digitized Production - Its Potentials and Hazards, ISPR 2018, Proceedings of the International Symposium for Production Research 2018, pp. 402-411, 2019.

[5] Durakbasa N.M., Osanna P.H.; Quality in Industry, Fourth Edition, ISBN 3-901888-23-3, 2009.

[6] Kozior, T.; \& Adamczak S.; Amplitude Surface Texture Parameters of Models Manufactured by FDM Technology, Proceedings of the International Symposium for Production Research 2018, pp. 208-217, 2019.

[7] Durakbasa N. M., Demircioglu P., Bodur. O., Poszvek G., Bogrekci I., Bas G., Bauer J.; Additive MiniaturizedManufactured Gear Parts Validated by Various Measuring Methods, IMEKOTC14 2019, LNME, pp. 276-290, 2019.

[8] Kaymaz Y., Kabasakal I., Çiçekli U., and Kocamaz M.; A Conceptual Framework for Developing a Customized I 4.0 Education Scale: An Exploratory Research, ISPR 2019, LNME, pp. 203-216, 2020.

[9] Majstorovic, V. D., Durakbasa N.M., Takaya Y. Stojadinovic S.; Advanced Manufacturing Metrology in Context of Industry 4.0 Model, IMEKOTC14 2019, LNME, pp. 1-11, 2019.

[10] Ozkeser, B., Karaarslan, C.; The Innovation Performance Under the Shadow of Industry 4.0, ., ISPR 2018, Proceedings of the International Symposium for Production Research 2018, pp. 494-502, 2019.

[11] ISO 10791-7; Test conditions for machining centres - Part 7: Accuracy of finished test pieces, Third edition, 2020

[12] ISO 2768 - 1; General tolerance - Part 1: Tolerances for linear and angular dimensions without individual tolerance indications, First edition, 1989-11-15.

[13] ISO 1101; Geometrical product specifications (GPS) - Geometrical tolerancing - Tolerances of form, orientation, location, and run-out, 2020.

[14] ISO 2768-2; General tolerances - Part 2: Geometrical tolerances for features without individual tolerance indications, First edition. 1989-11-15.

[15] VDI 3405; Additive manufacturing processes, rapid manufacturing, December 2014.

[16] ISO/ASTM 52900:2015; Additive manufacturing — General principles — Terminology, Publication date: 12-2015

[17] Zmarzły P., Adamczak S., Kozior T., Gogolewski D., Surface Texture Quality of Models Manufactured by Additive Technology Fused Deposition Modelling, 29th DAAAM International Symposium, pp.0853-0859, ISBN 978-3902734-20-4, ISSN 1726-9679, Vienna, Austria, 2018.

[18] ISO/ASTM FDIS 52915:2019; Specification for additive manufacturing file format (AMF) Version 1.2, Publication date: 10.2020 .

[19] Durakbasa N. M., Bauer J. M., Bodur O., Poszvek, G.; Challenges of Miniaturizing a Precision Gear, ISPR 2018, Proceedings of the International Symposium for Production Research 2018, pp. 239-253, 2019.

[20] ISO 3534-1; Statistics - Vocabulary and symbols - Part 1: General statistical terms and terms used in probability, 2006.

[21] ISO 3534-2; Test code for machine tools - Part 2: Determination of accuracy and repeatability of positioning numerically controlled axes, 2006.

[22] Bialas, S.; Osanna, P.H., Tamre, M.,Weckenmann, A., Blunt, L.; Geometrical Product Specification, ISBN 83912190-8-9, 2001. 